\title{
High fecal carriage of extended Beta Lactamase producing Enterobacteriaceae among adult patients admitted in referral hospitals in Dar es Salaam, Tanzania
}

\author{
Upendo O. Kibwana* (D, Mtebe Majigo, Doreen Kamori and Joel Manyahi
}

\begin{abstract}
Background: Multi-drug resistance pathogens such as Extended-Spectrum Beta-Lactamase (ESBL) producing Enterobacteriaceae (ESBL-PE) are of great global health concern, since they are associated with increased morbidity and mortality. Even in the absence of infections caused by these pathogens, colonization is a great threat and can lead to cross transfer among hospitalized patients. To date data on carriage of these pathogens is still limited in Tanzania. Therefore, this study aimed to determine ESBL-PE fecal carriage rate and associated factors among hospitalized patients at Referral hospitals in Dar es Salaam.

Methods: This was a cross sectional study conducted from May to July 2017 among patients admitted in three referral hospitals in Dar es Salaam, Tanzania. Rectal swabs were collected and screened for ESBL production using MacConkey agar supplemented with Ceftazidime $2 \mu \mathrm{g} / \mathrm{ml}$. Phenotypic confirmation of ESBL-PE was done by double disk diffusion method. Statistical analysis was performed using Statistical Package for Social Sciences (SPPS) software version 20.

Results: Of the 196 enrolled participants, 59.7\% (117/196) were confirmed to carry ESBL-PE. Diarrheic patients (57/ 79) had statistically significant high prevalence of ESBL colonization compared to those without diarrhea (60/117) $(p=0.01)$. A total of $131 \mathrm{ESBL}-\mathrm{PE}$ were isolated from 117 patients, whereby, Escherichia coli accounted for 68.7\%, Klebsiella pneumoniae 28.2\% and Citrobacter species 0.8\%. ESBL-PE carriage was significantly higher in patients with diarrhea compared to those without diarrhea ( $72 \%$ vs $53.1 \%, p=0.01$ ). Recent antibiotic use was independently associated with carriage of ESBL-PE (aOR 14.65, 95\%Cl 3.07-69.88, $p=0.01$ ).

Conclusions: High prevalence of fecal carriage of ESBL-PE was observed in patients admitted in tertiary hospitals in Dar es Salaam, Tanzania. The use of antibiotics was associated with carriage of ESBL producers among the study population.
\end{abstract}

Keywords: ESBL producing pathogen, Enterobacteriaceae, Tanzania

\footnotetext{
*Correspondence: pendokibwana@gmail.com

Department of Microbiology and Immunology, Muhimbili University of Health and Allied Sciences Dar es Salaam, P.O. Box 65001, Dar es Salaam, Tanzania
}

(c) The Author(s). 2020 Open Access This article is licensed under a Creative Commons Attribution 4.0 International License, which permits use, sharing, adaptation, distribution and reproduction in any medium or format, as long as you give appropriate credit to the original author(s) and the source, provide a link to the Creative Commons licence, and indicate if changes were made. The images or other third party material in this article are included in the article's Creative Commons licence, unless indicated otherwise in a credit line to the material. If material is not included in the article's Creative Commons licence and your intended use is not permitted by statutory regulation or exceeds the permitted use, you will need to obtain permission directly from the copyright holder. To view a copy of this licence, visit http://creativecommons.org/licenses/by/4.0/. The Creative Commons Public Domain Dedication waiver (http://creativecommons.org/publicdomain/zero/1.0/) applies to the data made available in this article, unless otherwise stated in a credit line to the data. 


\section{Background}

Extended-spectrum $\beta$-lactamase producing Enterobacteriaceae (ESBL-PE) infections poses a unique challenge to healthcare, as it is associated with mortality and morbidity [1]. These pathogens are increasingly implicated as causes of both community and hospital-acquired infections but even in the absence of infection, colonization with Extended-spectrum $\beta$-lactamase (ESBL) producing bacteria is a reason for concern $[2,3]$. In hospital settings, gastrointestinal carriage of ESBL, is the main reservoir of these organisms associated with high risk for developing self and cross infections [4].

ESBL-PE carriage and infections varies from different geographical locations, individual hospitals and different clinical conditions $[5,6]$. A recent study from Ethiopia reported prevalence of ESBL-PE colonization to be $52 \%$ among hospitalized patients [7]; admission unit, number of beds and number of patients per room were reported as factors associated with carriage of ESBL-PE in that study. Several studies in East Africa have also documented high rates of ESBL-PE from clinical settings [8, 9].

In Tanzania, some few studies have been conducted, mostly focusing on infections caused by ESBL producers among different populations, from children to adults with different clinical conditions [10, 11], but little is known about carriage rate of these pathogens among hospitalized patients where cross contamination can occur. In addition, there is also limited information about carriage of ESBL producing pathogens among adult patients with diarrhea in the study area which is important to know since ESBL production can also be observed in pathogens causing diarrhea such as, diarrhogenic E.coli $[12,13]$. Therefore, this study aimed to investigate ESBL-PE fecal carriage among hospitalized patients including those with diarrhea, and determine factors associated with their carriage in various referral hospitals in Dar es Salaam.

\section{Methods}

\section{Study design and settings}

This was a cross sectional study conducted from May to July 2017 in three hospitals, in Dar es Salaam, Tanzania. The study sites included Muhimbili National hospital $(\mathrm{MNH})$ the main specialized tertiary hospital with 1500bed capacity, admitting 150-180 patients per day of which $2 \%$ are due to diarrheal disease. In addition, Amana and Temeke, regional referral hospitals with 250-300 bed capacity each, admitting 50-70 patients per day of which $6-7 \%$ are due to diarrheal diseases.

\section{Study population, sample size and sampling procedure}

A total of 196 adult patients aged 18 years and above who were admitted in medical wards, Intensive Care
Unit (ICU) and isolation wards for more than $24 \mathrm{~h}$ were randomly selected and consecutively enrolled in this study.

\section{Data collection}

Structured questionnaires were used to collect study participants' clinical and demographic information. Information recorded included; age, sex, admission unit, diarrhea status, antibiotic use in the past 3 months, hospitalization history in the past 3 months, history of invasive procedures in the past 3 months and comorbidities.

\section{Specimen collection}

Trained nurses collected rectal swabs from consented participants and immediately put in Cary Blair transport media. The specimens were transported in a cool box with ice packs to Microbiology and Immunology Bacteriology research laboratory at Muhimbili University of Health and Allied Sciences (MUHAS) for processing.

\section{Laboratory investigations}

In the laboratory, rectal swabs were cultured immediately on MacConkey agar supplemented with Ceftazidime $2 \mu \mathrm{g} / \mathrm{ml}$ and incubated aerobically at $37^{\circ} \mathrm{C}$ for $24 \mathrm{~h}$ as a screening test for ESBL-PE [14]. Isolated bacteria were identified based on colonial morphology, Gram staining and a set of conventional biochemical tests which included, Indole, Citrate, Sulphur Indole Motility (SIM) as described elsewhere [15] and API 20E tests.

Isolated organisms in screening test were potentially considered as ESBL-PE; however, they were further confirmed by double disk diffusion method [16]. Briefly, both ceftazidime $(30 \mu \mathrm{g})$ and cefotaxime $(30 \mu \mathrm{g})$, alone and in combination with clavulanate $(10 \mu \mathrm{g})$ were placed into inoculated Muller Hinton Agar (MHA) plate with test organism and incubated at $37^{\circ} \mathrm{C}$ aerobically for 18 h. The zones of inhibition were observed and interpreted according to Clinical and Laboratory Standards Institute (CLSI) 2015 guidelines. ESBL-PE was confirmed when there was $\geq 5 \mathrm{~mm}$ increase in a zone diameter for either antimicrobial agent tested in combination with clavulanate versus when tested alone [16]. Klebsiella pneumoniae ATCC 700603 was used as a positive control.

\section{Antibiotic susceptibility test}

The confirmed ESBL-PE isolates were tested for antimicrobial susceptibility using Kirby-Bauer disk diffusion method according to CLSI guidelines [16]. Briefly, homogenous colonial suspensions were prepared using 3-5 colonies from a pure culture comparable to 0.5 McFarland turbidity standard. Standardized suspensions were inoculated on MHA, and then incubated at $37^{\circ} \mathrm{C}$ aerobically for $24 \mathrm{~h}$. The zones of inhibition were 
interpreted according to CLSI guidelines. E. coli ATCC 25922 was used as a positive control organism. The disks used included: chloramphenicol $(20 \mu \mathrm{g})$, gentamicin $(10 \mu \mathrm{g})$, ciprofloxacin $(5 \mu \mathrm{g})$, trimethoprim/sulfamethoxazole $(1.25 / 23.75 \mu \mathrm{g})$, tetracycline $(30 \mu \mathrm{g})$ (Oxoid, UK).

\section{Data analysis}

Data analysis was performed using statistical package for social science (SPSS) version 20. Categorical variables were summarized in a form of frequencies and percentages. Fisher's exact test was employed to compare the associated factors for ESBL-PE. $P$-value $<0.05$ was considered as statistically significant. Binary simple logistic regression was first performed to determine the factors associated with ESBL-PE followed by multivariable regression model to determine factors independently associated with ESBL-PE carriage. Adjusted odds ratio was used to describe strength of association at 95\% confidence intervals. $P$-value $<0.05$ was considered as statistically significant.

\section{Results}

\section{Description of study participants}

A total of 196 inpatients were enrolled, with age range from 18 to 62 years and median age of 25 (IQR: 18-30) years. Half of the study participants were aged between 18 and 27 years, and those above 57 years were the least (0.5\%). Most of participants $61.7 \%$ (121/196) were females and Medical ward unit contributed majority of patients accounting for $78.6 \%$. Nearly half of participants (46.9\%) had history of previous antibiotic use in the past 3 months and $18.4 \%$ had history of invasive procedures in the past 3 months majority of them (55.6\%) being catheterization. Seventy-nine patients $(40.3 \%)$ had diarrhea and 36 patients (18.4\%) were HIV positive (Table 1).

\section{Distribution of ESBL producing Enterobacteriaceae carriage}

Screening and phenotypic testing of isolates obtained from rectal swab specimen for ESBL-PE revealed that the overall fecal carriage of ESBL-PE was 59.7\% (117/ 196). Majority of study participants colonized by ESBLPE aged between 38 and 47 years (68\%) and there was no significant difference in carriage between the age groups. Diarrheic patients $57(72 \%)$ had higher colonization rate than those without diarrhea and the difference was statistically significant $(p=0.01)$. There was also a significant high carriage in patients admitted at Amana hospital (80\%), compared to Temeke hospital and Muhimbili National hospital $(p=0.004)$. Further analysis stratification revealed that higher carriage rate in patients admitted in medical wards (61\%) compared
Table 1 Socio-demographics and clinical Characteristics of study participants

\begin{tabular}{|c|c|c|}
\hline Variables & Frequency/Median & Percentage (\%) \\
\hline \multicolumn{3}{|l|}{ Median age 25} \\
\hline \multicolumn{3}{|c|}{ Age group in years } \\
\hline $18-27$ & 98 & 50.0 \\
\hline $28-37$ & 68 & 35.0 \\
\hline $38-47$ & 22 & 11.0 \\
\hline$>47$ & 8 & 4.0 \\
\hline \multicolumn{3}{|l|}{ Sex } \\
\hline Female & 121 & 67.7 \\
\hline Male & 75 & 35.3 \\
\hline \multicolumn{3}{|l|}{ Study Site } \\
\hline Temeke & 166 & 84.7 \\
\hline Amana & 20 & 10.2 \\
\hline MNH & 10 & 5.1 \\
\hline \multicolumn{3}{|l|}{ Admission Unit } \\
\hline Medical ward & 154 & 78.6 \\
\hline Isolation Unit & 35 & 17.9 \\
\hline ICU & 7 & 3.5 \\
\hline \multicolumn{3}{|l|}{ Diarrhea Status } \\
\hline Yes & 79 & 40.3 \\
\hline No & 117 & 50.7 \\
\hline \multicolumn{3}{|c|}{ Antibiotic use in the past 3 months } \\
\hline Yes & 92 & 46.9 \\
\hline No & 104 & 53.1 \\
\hline \multicolumn{3}{|c|}{ Hospitalization in the past 3 months } \\
\hline Yes & 70 & 35.8 \\
\hline No & 126 & 64.2 \\
\hline \multicolumn{3}{|c|}{ Invasive procedure in past 3 months } \\
\hline Yes & 36 & 18.4 \\
\hline No & 160 & 81.6 \\
\hline \multicolumn{3}{|c|}{ Type of Invasive procedure } \\
\hline Catheterization & 20 & 55.6 \\
\hline Surgery & 16 & 44.4 \\
\hline \multicolumn{3}{|l|}{ HIV status } \\
\hline Positive & 36 & 18.4 \\
\hline Negative & 160 & 81.6 \\
\hline
\end{tabular}

to ICU (57.1\%) and isolation units $(60 \%) \quad(p=0.01)$ (Table 2).

\section{Bacteria isolates and antimicrobial resistance pattern of ESBL-PE}

Among 131 bacteria isolates confirmed as ESBL producers, E coli (68.7\%) and K. pneumoniae (28.2\%) were the most frequent isolated bacteria. All isolated ESBL-PE showed high co-resistance to antibiotics tested (Table 3). 
Table 2 Distribution of ESBL producing Enterobacteriaceae among study participants

\begin{tabular}{|c|c|c|c|}
\hline \multirow[t]{2}{*}{ Characteristics } & \multirow[t]{2}{*}{$\boldsymbol{N}=196$} & \multicolumn{2}{|c|}{ Proportion of ESBL-PE carriage } \\
\hline & & $\overline{n(\%)}$ & $p$-value \\
\hline \multicolumn{4}{|l|}{ Overall $59.7 \%$} \\
\hline \multicolumn{4}{|l|}{ Gender } \\
\hline Male & 75 & $43(57.3)$ & 0.780 \\
\hline Female & 121 & $74(61.2)$ & \\
\hline \multicolumn{4}{|c|}{ Age groups (years) } \\
\hline $18-27$ & 98 & $56(57.1)$ & \\
\hline $28-37$ & 68 & $42(61.8)$ & \\
\hline $38-47$ & 22 & $15(68.2)$ & 0.592 \\
\hline$>47$ & 8 & $4(50.0)$ & \\
\hline \multicolumn{4}{|l|}{ Study Site } \\
\hline Temeke & 166 & $95(57)$ & \\
\hline Amana & 20 & $16(80)$ & 0.004 \\
\hline $\mathrm{MNH}$ & 10 & $6(60)$ & \\
\hline \multicolumn{4}{|l|}{ Study Unit } \\
\hline Medical Ward & 154 & $92(61)$ & \\
\hline Isolation Ward & 35 & $21(60)$ & 0.001 \\
\hline $\mathrm{ICU}$ & 7 & $4(57.1)$ & \\
\hline \multicolumn{4}{|l|}{ Diarrhea Status } \\
\hline Yes & 79 & $57(72)$ & 0.001 \\
\hline No & 117 & $60(53.1)$ & \\
\hline
\end{tabular}

Highest resistance totrimethoprim/sulfamethoxazole (> 85\%) was observed in all isolates. E. coli displayed high rates of resistance to Gentamycin (82.1\%), Ciprofloxacin (66.3\%, Chloramphenicol (77.9\%) trimethoprim/sulfamethoxazole/ (85.3\%) and Tetracycline (84.2\%).

\section{Factors associated with carriage of ESBL-PE}

Analysis was performed to determine the factors associated with carriage of ESBL-PE. Patients exposed to antibiotics up to 3 months prior to hospitalization were significantly associated with colonization by ESBL-PE (cOR 10.7, 95\% CI, 2.90-39.42, $p=0.00$ ). There was no significant association between carriage of ESBL-PE and patients with history of previous hospital admission in the past 3 months as well as HIV status. On multivariable analysis, previous antibiotic use for the past 3 months was found to be independently associated with the carriage of ESBL-PE (aOR 14.65, 95\% CI 3.07-69.88, $p=0.01$ ) (Table 4). An additional excel file describes all results in more detail (see additional file 1).

\section{Discussion}

In the present study we demonstrate high carriage rate of ESBL producing pathogens among hospitalized patients which is associated with previous antibiotic use. We further demonstrate high rates among patients with diarrhea compared to patients admitted with other conditions. The overall carriage rate $(57.9 \%)$ in our study is comparable to findings from hospitalized adults in Ethiopia (52\%) and Rwanda (50\%) [7, 17]. However, our finding is slightly higher compared to that reported among hospitalized patients by Sabrina et al. in Dar es Salaam, Tanzania [11]. Potential reasons for the observed difference include several factors such as; different ESBL detection techniques and specimen used, whereas in a study by Sabrina et al. they used urine specimen and ESBL-E test strip for ESBL detection. Furthermore the carriage rate in our study is also higher compared to that reported among hospitalized children in Dar es Salaam, Tanzania [18]. This difference may be accounted for by the difference in study population, whereby the participants in that study were children versus adults in our study. Being adults, our study participants are likely to have been exposed to risk factors for carriage of ESBL-PE, like previous hospitalization and antibiotic use including self-prescription compared to children. In Uganda, a much higher colonization rate of $62 \%$ has been reported [19]. The variation between our study and this study may be due to differences in study population, specimen taken, clinical conditions of the participants, factors which are known to cause variation in ESBL-PE colonization patterns as documented by others [20, 21].

Among the ESBL-PE colonized patients in our study, those with diarrhea had higher carriage rate compared to those without diarrhea. These results are similar to what others have reported $[6,22]$. However, in a study

Table 3 Antimicrobial resistance pattern of isolated ESBL-PE

\begin{tabular}{|c|c|c|c|}
\hline Antibiotic & E. coli $\%(\boldsymbol{N}=90)$ & K. pneumoniae $\%(\boldsymbol{N}=37)$ & K. oxytoca \% $(N=3)$ \\
\hline Gn & 82.1 & 82.4 & 66.7 \\
\hline Cip & 66.3 & 73.5 & 66.7 \\
\hline C & 77.9 & 67.6 & 66.7 \\
\hline Sxt & 85.3 & 97.1 & 100 \\
\hline Tet & 84.2 & 91.2 & 100 \\
\hline
\end{tabular}

Gn gentamicin, Cip ciprofloxacin, C chloramphenicol, Sxt trimethoprim/sulfamethoxazole/, Tet Tetracycline 
Table 4 Univariate and Multivariate analysis of factors associated with fecal carriage of ESBL producing Enterobacteriaceae

\begin{tabular}{|c|c|c|c|c|c|c|}
\hline \multirow[t]{3}{*}{ Characteristics } & \multirow[t]{3}{*}{$\boldsymbol{N}=129$} & \multirow{3}{*}{$\begin{array}{l}\mathrm{n}(\%) \\
=117\end{array}$} & \multicolumn{4}{|c|}{ Proportion of ESBL carriage } \\
\hline & & & \multicolumn{2}{|l|}{ Univariate } & \multicolumn{2}{|l|}{ Multivariate } \\
\hline & & & $\operatorname{cOR}(95 \%)$ & $\boldsymbol{p}$ value & $\mathrm{aOR}(95 \%)$ & $\boldsymbol{p}$ value \\
\hline Gender & & & $1^{a}$ & & & \\
\hline Male & 48 & $43(89.6)$ & & & & \\
\hline Female & 81 & $74(91.4)$ & $1.23(0.37-4.11)$ & 0.74 & & \\
\hline \multicolumn{7}{|l|}{ Age group in years } \\
\hline & 116 & $105(90.5)$ & $1^{\mathrm{a}}$ & & & \\
\hline & 13 & $12(92.3)$ & $1.26(0.15-10.60)$ & 0.83 & & \\
\hline \multicolumn{7}{|c|}{ Antibiotic use in the past 3 months } \\
\hline No & 16 & $10(62.5)$ & $1^{a}$ & & & \\
\hline Yes & 113 & $107(94.7)$ & $10.7(2.90-39.42)$ & 0.00 & $14.65(3.07-69.88)$ & 0.01 \\
\hline \multicolumn{7}{|c|}{ Hospitalization in the past 3 months } \\
\hline No & 87 & $78(89.7)$ & $1^{a}$ & & & \\
\hline Yes & 42 & $39(92.9)$ & $1.50(0.38-5.86)$ & 0.56 & & \\
\hline \multicolumn{7}{|c|}{ Invasive procedures in the past 3 months } \\
\hline No & 95 & $87(88.4)$ & $1^{\mathrm{a}}$ & & & \\
\hline Surgery & 13 & $12(92.3)$ & $1.26(0.15-10.61)$ & 0.83 & & \\
\hline Catheterization & 21 & $18(85.7)$ & $1.833(0.45-7.43)$ & 0.4 & & \\
\hline \multicolumn{7}{|l|}{ Chronic disease } \\
\hline No & 120 & $90(75.0)$ & $1^{\mathrm{a}}$ & & & \\
\hline Yes (HIV/AIDS, PTB, Diabetes) & 29 & $27(92.3)$ & $1.30(0.27-6.28)$ & 0.75 & & \\
\hline
\end{tabular}

$\mathrm{N}$ : Total number of patients subjected to confirmatory ESBL test, $\mathrm{n}$ : number of patients confirmed to carry ESBL producing pathogens, $1^{\mathrm{a}}$ : reference category, $C O R$ crude odds ratio, aOR adjusted odds ratio, HIV Human Immunodeficiency Virus, AIDS Acquired Immunodeficiency Syndrome, PTB Pulmonary Tuberculosis

done among children by Tellevic and his colleagues, children hospitalized due to diarrhea had lower carriage rate compared to those hospitalized due to other diseases, probably because the latter group included children with many diverse conditions [18]. The pattern observed in our study can be explained by the fact that diarrhea cause changes in the gut microbiota which provides conducive environment for exchange of resistance genes between inter and intra species including the indigenous organisms [23].

In an attempt to investigate factors associated with ESBL-PE carriage, previous antibiotic use in the past 3 months was identified as a significant factor associated with carriage of ESBL. Our findings are in agreement with previous studies done in Rwanda [17, 24]. This observation might be reflecting the result of irrational use of these antibiotic agents in the study population that eventually may lead to high selection pressure of resistant bacteria.

In line with reports from Sudan [25] and Mali [26], Escherichia coli was the most predominant ESBL producer isolated in our study. Cross-resistance of ESBLs to other drug classes such as aminoglycosides and fluoroquinolones has been previously documented [27-29]. Findings from this study corroborates with that, as it indicated a high co-resistance pattern to those antibiotic classes in all tested isolates. This pattern is however higher than findings from Ethiopia [7]. This may be explained by the fact that the plasmids carrying genes for ESBL production which was observed to be high in this study was also carrying co- resistance genes for other antibiotics. Highest resistance of antibiotics was observed in trimethoprim/ sulfamethoxazole/ and tetracycline in all isolated ESBL$\mathrm{PE}$, these findings are consistent with reports from one study in Uganda [30]. The high resistance pattern observed in this study could reflect frequent use of over the counter medicine and self-medication practices in the study settings. This result indicates the need for guided treatment following culture results. A limitation of this study was a failure to perform molecular tests for characterization of ESBL genes from isolated pathogens.

\section{Conclusion}

This study revealed high prevalence of fecal carriage of ESBL-PE among hospitalized patients especially among those with diarrhea. Previous antibiotic use was associated with carriage of ESBL-PE. ESBL producing isolates expressed high resistance to other commonly used antibiotics. 


\section{Supplementary information}

Supplementary information accompanies this paper at https://doi.org/10. 1186/s12879-020-05272-4.

Additional file 1. Raw data for ESBL-PE among adult patients in Dar es Salaam Tanzania. Additional file 1 is an excel spreadsheet with the data obtained from admitted adult patients in three different hospitals in Dar es salaam Tanzania. All provided data was analyzed using SPSS software and generated results reported in this manuscript.

\section{Abbreviations}

AIDS: Acquired Immunodeficiency Syndrome; AST: Antimicrobial Susceptibility Testing; ATCC: American Type Culture Collection; CLSI: Clinical Laboratory Standard Institute; ESBL: Extended Spectrum Beta Lactamase; ESBL-PE: Extended Spectrum Beta Lactamase producing Enterobacteriaceae; HIV: Human Immunodeficiency Virus; MHA: Muller Hinton Agar; MUHAS: Muhimbili University of Health and Allied Sciences; SPSS: Statistical Package for Social Sciences; UK: United Kingdom

\section{Acknowledgements}

The authors would like to acknowledge all patients who participated in this study. We also thank nurses from Muhimbili, Temeke and Amana hospitals who assisted with patient recruitment and specimen collection.

\section{Authors' contributions}

UK, JM, and MM participated in conception and study design. UK was responsible for data collection and laboratory testing. UK, JM, MM and DK were involved in data analysis. UK, JM, MM and DK were involved in drafting of the manuscript. All the authors read and approved the final version.

\section{Funding}

This study received financial support from Professor Lance of University of Virginia. The funder had no role in study design selection, collection, analysis, interpretation of data and in manuscript writing.

\section{Availability of data and materials}

All relevant data generated and analyzed during this study are included in this manuscript.

\section{Ethics approval and consent to participate}

Ethical clearance to undertake this study was obtained from the Senate Research and Publications Committee of Muhimbili University of Health and Allied Sciences (MUHAS). Permission to conduct the study was sought from $\mathrm{MNH}$, Mwananyamala and Temeke regional referral hospitals. Written informed consent were obtained from all study participants before enrollment into the study.

\section{Consent for publication}

Not applicable.

\section{Competing interests}

The authors declare that they have no competing interests.

Received: 18 July 2019 Accepted: 20 July 2020

Published online: 31 July 2020

\section{References}

1. Rupp ME, Fey PD. Extended spectrum beta-lactamase (ESBL)-producing Enterobacteriaceae: considerations for diagnosis, prevention and drug treatment. Drugs. 2003;63(4):353-65.

2. Isendahl J, Turlej-Rogacka A, Manjuba C, Rodrigues A, Giske CG, Nauclér P. Fecal Carriage of ESBL-Producing E. coli and K. pneumoniae in Children in Guinea-Bissau: A Hospital-Based Cross-Sectional Study. Conly J, editor. PLoS One. 2012;7(12):e51981

3. Schwaber MJ, Lev B, Israeli A, Solter E, Smollan G, Rubinovitch B, et al. Containment of a country-wide outbreak of Carbapenem-resistant Klebsiella pneumoniae in Israeli hospitals via a nationally implemented intervention. Clin Infect Dis. 2011;52(7):848-55.

4. Andriatahina T, Randrianirina F, Hariniana ER, Talarmin A, Raobijaona $\mathrm{H}_{\text {, }}$ Buisson $Y$, et al. High prevalence of fecal carriage of extended-spectrum beta-lactamase-producing Escherichia coli and Klebsiella pneumoniae in a pediatric unit in Madagascar. BMC Infect Dis. 2010;10:204.

5. Woerther P-L, Burdet $C$, Chachaty E, Andremont A. Trends in human fecal carriage of extended-spectrum $\beta$-lactamases in the community: toward the globalization of CTX-M. Clin Microbiol Rev. 2013;26(4):744-58.

6. Valverde A, Grill F, Coque TM, Pintado V, Baquero F, Cantón R, et al. High rate of intestinal colonization with extended-spectrum-beta-lactamaseproducing organisms in household contacts of infected community patients. J Clin Microbiol. 2008;46(8):2796-9.

7. Desta K, Woldeamanuel Y, Azazh A, Mohammod H, Desalegn D, Shimelis D, et al. High Gastrointestinal Colonization Rate with Extended-Spectrum $\beta$ Lactamase-Producing Enterobacteriaceae in Hospitalized Patients: Emergence of Carbapenemase-Producing K. pneumoniae in Ethiopia. PLoS One. 2016;11(8):16.

8. Oduro-Mensah D, Obeng-Nkrumah N, Bonney EY, Oduro-Mensah E, TwumDanso K, Osei YD, et al. Genetic characterization of TEM-type ESBLassociated antibacterial resistance in Enterobacteriaceae in a tertiary hospital in Ghana. Ann Clin Microbiol Antimicrob. 2016;15:29.

9. Sonda $T$, Kumburu $H$, van Zwetselaar $M$, Alifrangis $M$, Lund $O$, Kibiki $G$, et al. Meta-analysis of proportion estimates of Extended-Spectrum-BetaLactamase-producing Enterobacteriaceae in East Africa hospitals. Antimicrob Resist Infect Control. 2016;5:18.

10. Mshana SE, Kamugisha E, Mirambo M, Chakraborty T, Lyamuya EF. Prevalence of multiresistant gram-negative organisms in a tertiary hospital in Mwanza, Tanzania. BMC Res Notes. 2009;2(1):49.

11. Moyo SJ, Aboud S, Kasubi M, Lyamuya EF, Maselle SY. Antimicrobial resistance among producers and non-producers of extended spectrum beta-lactamases in urinary isolates at a tertiary Hospital in Tanzania. BMC Res Notes. 2010;3(1):348.

12. Manyahi J, Matee MI, Majigo M, Moyo S, Mshana SE, Lyamuya EF. Predominance of multi-drug resistant bacterial pathogens causing surgical site infections in Muhimbili National Hospital, Tanzania. BMC Res Notes. 2014;7:500.

13. Lautenbach E, Han J, Santana E, Tolomeo P, Bilker WB, Maslow J. Colonization with extended-spectrum $\beta$-lactamase-producing Escherichia coli and Klebsiella species in long-term care facility residents. Infect Control Hosp Epidemiol. 2012;33(3):302-4.

14. Wilson G, Mccabe D. The use of antibiotic-containing agars for the isolation of extended-spectrum $\beta$-lactamase-producing organisms in intensive care units. Clin Microbiol Infect. 2007;13(4):451-3.

15. Cheesbrough M. District Laboratory Practice in Tropical Countries Part 2. 2nd ed. Cambridge University Press; 2006. p. 440p.

16. Wayne P. M100-S25 performance Standards for Antimicrobial Susceptibility; 2015

17. Kurz MSE, Bayingana C, Ndoli JM, Sendegeya A, Durst A, Pfüller R, et al. Intense pre-admission carriage and further acquisition of ESBL-producing Enterobacteriaceae among patients and their caregivers in a tertiary hospital in Rwanda. Trop Med Int Heal. 2017 Feb;22(2):210-20.

18. Tellevik MG, Blomberg B, Kommedal Ø, Maselle SY, Langeland N, Moyo SJ. High prevalence of Faecal carriage of ESBL-producing Enterobacteriaceae among children in Dar Es Salaam, Tanzania. PLoS One. 2016;11(12): e0168024.

19. Kateregga JN, Kantume R, Atuhaire C, Lubowa MN, Ndukui JG. Phenotypic expression and prevalence of ESBL-producing Enterobacteriaceae in samples collected from patients in various wards of Mulago hospital. Uganda BMC Pharmacol Toxicol. 2015;16(1):14.

20. Kanafani Z. A M, Araj G, Kanaan M, kanji S. epidemiology and risk factors for extended-spectrum $\beta$-lactamase-producing organisms: a case control study at a tertiary care center in Lebanon. Am J Infect Control. 2005;33(6):326-32

21. Jaggi N, Sissodia P, Sharma L. Control of multidrug resistant bacteria in a tertiary care hospital in India. Antimicrob Resist Infect Control. 2012;1(1):23.

22. Tham J, Odenholt I, Walder M, Brolund A, Ahl J, Melander E. Extendedspectrum beta-lactamase-producing Escherichia coli in patients with travellers' diarrhoea. Scand J Infect Dis. 2010;42(4):275-80.

23. Tham J, Walder M, Melander E, Odenholt I. Duration of colonization with extended-spectrum beta-lactamase-producing Escherichia coli in patients with travellers' diarrhoea. Scand J Infect Dis. 2012;44(8):573-7.

24. Fouda R, Soliman MS, ElAnany MG, Abadeer M, Soliman G. Prevalence and risk factors of MRSA, ESBL and MDR bacterial colonization upon admission to an Egyptian medical ICU. J Infect Dev Ctries. 2016;10(4):329-36. 
25. Ibrahim ME, Bilal NE, Hamid ME. Increased multi-drug resistant

Escherichia coli from hospitals in Khartoum state, Sudan. Afr Health Sci. 2012;12(3):368-75.

26. Sangare SA, Maiga Al, Guindo I, Maiga A, Camara N, Savadogo S, et al. Prevalence of extended-spectrum beta-lactamase-producing Enterobacteriaceae isolated from blood cultures in Africa. Médecine Mal Infect. 2015;45(9):374-82.

27. Marbou WJT, Kuete V. Bacterial resistance and immunological profiles in HIV-infected and non-infected patients at Mbouda AD LUCEM Hospital in Cameroon. J Infect Public Health. 2017;10(3):269-76.

28. Schaumburg F, Alabi A, Kokou C, Grobusch MP, Kock R, Kaba H, et al. High burden of extended-spectrum -lactamase-producing Enterobacteriaceae in Gabon. J Antimicrob Chemother. 2013;68(9):2140-3.

29. Lonchel CM, Melin P, Gangoué-Piéboji J, Assoumou M-CO, Boreux R, Mol P. Extended-spectrum $\beta$-lactamase-producing Enterobacteriaceae in Cameroonian hospitals. Eur J Clin Microbiol Infect Dis. 2013;32(1):79-87.

30. Najjuka CF, Kateete DP, Kajumbula HM, Joloba ML, Essack SY. Antimicrobial susceptibility profiles of Escherichia coli and Klebsiella pneumoniae isolated from outpatients in urban and rural districts of Uganda. BMC Res Notes. 2016;9:235.

\section{Publisher's Note}

Springer Nature remains neutral with regard to jurisdictional claims in published maps and institutional affiliations.

Ready to submit your research? Choose BMC and benefit from:

- fast, convenient online submission

- thorough peer review by experienced researchers in your field

- rapid publication on acceptance

- support for research data, including large and complex data types

- gold Open Access which fosters wider collaboration and increased citations

- maximum visibility for your research: over $100 \mathrm{M}$ website views per year

At BMC, research is always in progress.

Learn more biomedcentral.com/submissions 